\title{
Indonesian Implicit Leadership Theory: Typical and Positive Leadership Prototypes for Indonesian Millennials
}

\author{
Rizqi Nur'aini A'yuninnisa ${ }^{1 \rtimes}$ (iD)
Muhammad Fashih Hibatul Haqqi ${ }^{2}$ (D) \\ Rizqi Nur'aini A'yuninnisa ${ }^{1 \rtimes}$ (iD)
Muhammad Fashih Hibatul Haqqi ${ }^{2}$ (iD \\ Nisfi Balqish Rusli ${ }^{3}$ (iD \\ Nabila Puteri ${ }^{4}$ (D)
}

${ }^{1,2, s, 4}$ Center for Indigenous and Cultural Psychology, Faculty of Psychology, Universitas Gadjah Mada, Indonesia. 'Email: rizqiavuninnisa@ugm.ac.id Email:m.fashih@mailugmacid

'Email: nisfibalqish@omailcom

Email:nabila.puteri.abel@gmail.com

\section{Abstract}

Leadership studies in Indonesia tend to discuss the way leadership affects individual attitudes and behavior as well as team effectiveness. However, a more contextual and recent approach study in understanding leadership remains underdeveloped. As a preliminary, this study aims to explore the concept of Indonesia's leadership based on local perspectives by taking into account Implicit Leadership Theory. Data were gathered by involving 404 millennials (63,6\% female, 36,4\% male) using an open-ended question namely "Describe three characteristics of a leader" and two scales asking participants' perception about how typical and effective each leaders' characteristic count for leadership. A total of 1159 responses were analyzed using thematic analysis and demonstrated four characteristics depicting prototypes of leaders namely moral $(41,07 \%)$, generally-competent $(29,42 \%)$, charismatic $(20,79 \%)$, conscientious $(8,71 \%)$. A one-way ANOVA was also conducted to compare the effect of leader's prototypes on perception of typicality and effectiveness of leadership. There was a significant effect of leadership prototypes on perception of typical leadership at the $\mathrm{p}<.05$ level for the three conditions for each of perception about how typical and effective the prototypes reflect leadership. However, at the level of prototypes, no differences were found in perceiving which prototypes were considered as more typical and effective. The descriptive scores of each prototype indicates all of the prototypes were perceived as high in reflecting typicality and effectiveness in leadership. In conclusion, all leadership prototypes emerged from the responses were perceived as both typical and effective by the participants.

Keywords: Leadership, Indonesian millennials, Leadership prototype, Implicit leadership theory, Effective leadership.

JEL Classification: D23, Eoo.

Citation | Rizqi Nur'aini A’yuninnisa; Muhammad Fashih Hibatul Haqqi; Nisfi Balqish Rusli; Nabila Puteri (2020). Indonesian Implicit Leadership Theory: Typical and Positive Leadership Prototypes for Indonesian Millennials. Asian Journal of Social Sciences and Management Studies, 7(1): 1-7.

History:

Received: 8 November 2019

Revised: 11 December 2019

Accepted: 15 January 2020

Published: 27 February 2020

Licensed: This work is licensed under a Creative Commons

Attribution 3.0 License (cc)

Publisher: Asian Online Journal Publishing Group
Acknowledgement: All authors contributed to the conception and design of the study.

Funding: This study received no specific financial support.

Competing Interests: The authors declare that they have no conflict of interests.

Transparency: The authors confirm that the manuscript is an honest, accurate, and transparent account of the study was reported; that no vital features of the study have been omitted; and that any discrepancies from the features of the study have been omitted;
study as planned have been explained.

Ethical: This study follows all ethical practices during writing.

\section{Contents}

1. Introduction

2. Method

3. Result.

4. Discussion

5. Conclusion

6. Limitation \& Future Research

References... 


\section{Contribution of this paper to the literature}

This study contributes to the existing literature by exploring Indonesian Implicit Theory by taking into account typical norm and positive valence of leadership prototypes from the local perspective of Indonesia.

\section{Introduction}

Leadership effectiveness has been found to be influenced by affective, behavioral, and cognitive domains of individuals which is considered as a complex emergence (Avolio, Walumbwa, \& Weber, 2009; Day, Fleenor, Atwater, Sturm, \& McKee, 2014). This complexity is sharpened by its dependency on the context where leadership occurs. A study of Global Leadership and Organizational Behavior Project (GLOBE) involving 22 countries showed that there were certain prototypes of effective leader which could be found in one country but not the others. Such phenomenon occurred as the result of cognitive framework of individuals with diverse social cultural and economic backgrounds (Brodbeck et al., 2000).

In Indonesia, leadership studies which take into account social and cultural context into consideration are still limited. Most of studies in Indonesia tend to focus on proving the way effective leadership influences individual's attitudes and behaviors, such as job satisfaction, job commitment, and so on (Harwiki, 2013; Helmi \& Arisudana, 2009; Suseno \& Sugiyanto, 2010; Widianto \& Wilderom, 2017). More fundamental leadership studies to explore the concept of leadership and Indonesian people understanding toward leadership, to our knowledge, have not been fully identified and developed.

One of very few exploratory research about leadership in Indonesian local culture was conducted by As'Ad, Anggoro, and Virdanianty (2011) exploring leadership using a concept in Javanese culture. The study was initiated by a concern about contextual difference between Western and Eastern cultures which could result in different psychological phenomena, including leadership. Western concepts and theories of leadership might not be relevant and applicable in the East, so does the instruments measuring leadership. With this background, the study was conducted to explore a leadership concept derived from Indonesian culture, which is Javanese leadership model and principles known as Astha Bratha. Unfortunately, this study was limited to trait approach by demonstrating traits that should be possessed by leaders according to ancient Javanese scripts. In addition, the study did not adequately delve into the perception and expectation of people toward their leaders. Based on the development of leadership theories, trait paradigm is not effective in describing leadership as it tends to simplify the construction of leadership solely on human's innate characteristics. The paradigm is considered pessimistic because it does not consider the possibility that leader can be developed (Ronald, 2014). Nowadays, leadership theory that still develops as a research topic is Implicit Leadership Theory (ILT). This theory can explain the mechanism of effective leadership within certain cultural context according to cognitive frameworks of its followers (Offermann \& Coats, 2018).

The development of ILT started from the concept of cognitive categorization (Rosch, 1978) which was the basis of theory of leadership categorization (Lord, Foti, \& Phillips, 1982; Robert, Foti, \& De Vader, 1984). Lord and his colleagues explained that implicit theory of leadership reflects the structures and contents of cognitive categorization done by an individual in order to distinguish leader and non-leader. A person can quickly label others as "leader" or "non-leader" according to certain characteristics which has been categorized in his/her cognitive function (Phillips \& Lord, 1986). The fundamental category regularly used to define those characteristics is called prototype. Thus in ILT, leadership prototypes provide information about certain characteristics to identify leadership (Offermann., Kennedy, \& Wirtz, 1994).

Junker and van Dick (2014) explained that leadership prototypes owned by someone will influence his or her thinking process and behavior as followers, even unconsciously. This ILT can cause bias in perceiving leader's objective behaviors which then could affect their objective appraisal toward effectiveness of the leader. Moreover, a follower will be more satisfied while working under the leadership of individual who fits his or her leadership prototypes. In other words, ILT may influence the perception of effective leadership and well-being of the team emerged from interaction between leader and follower.

Further, Junker and van Dick (2014) elaborated that in general, leadership prototypes are categorized into two dimensions: norm and valence of prototypes. Norm of prototype represents the typical or ideal of a leader. Typical prototypes show the general prototypes or characters found in a leader, while ideal prototypes illustrate highly desirable characters which are only owned by small number of leaders. Meanwhile, valence of prototype points toward the positive, negative, and neutral perceptions on leadership prototypes. Positive prototypes describe preferable attributes that would support effective leadership while negative prototypes are non-desirable characters that would hinder effective leadership. Neutral prototype refers to irrelevant attributes in leadership.

Related to the previous dimensions of prototype, Schyns and Schilling (2011) showed that in various ILT studies, prototypes often come up showing typical and normative characteristics that are not always considered to reflect effective attributes of leadership. Thus, Schyns and Schlling recommended that during exploratory study in ILT, researcher needs to consider varieties of prototypes, not only the common ones, but also those that show effective leadership.

Based on the review of limitation of leadership studies that fit Indonesian context, this study aimed to explore the concept of leadership in Indonesia according to Implicit Leadership Theory. The goal of this study was to suggest which characteristics perceived by Indonesians to reflect leadership by taking into account typical norm of prototypes that reflect typical characteristics of leaders and positive valence of prototypes that indicate effectiveness. This study focused on Indonesian Millennials who were born in 1980 to 2000 , considering the fact that they have dominated the working age population in the country (Central Statistics Agency, 2013). In several years from now, they will be the leaders in the society. 


\section{Method}

\subsection{Study Design and Participants}

Researchers conducted survey to obtain data by distributing several open-ended questions and scales to explore the leadership prototypes from millennial perspective. Purposive convenience sampling was applied in recruiting Indonesian millennial online. Participants who came from various regions in Indonesia were recruited by using an online survey distributed through several social media platforms: WhatsApp, Line, and Instagram. To recruit more participants, researchers employed snowball method by encouraging social media users to participate in the study then circulated the online survey to their acquaintances. Participants in the study were millennial who were born in 1980 to 2000 (Barford \& Hester, 2011) aged from 19 to 39 years old $(\mathrm{M}=23.25)$. Researchers obtained 423 participants in total and those who fit millennial category were 404 participants $(36.4 \%$ male and 63.6\% female participants). Most participants were undergraduate students who had experiences in organization. Table 1 describes the demographic information of study's participants.

\begin{tabular}{|c|c|c|}
\hline \multicolumn{2}{|c|}{ Category } & \multirow[t]{2}{*}{$\mathbf{N}$} \\
\hline \multirow[t]{3}{*}{1.} & Sex & \\
\hline & Male & $147^{1}(36.4)^{2}$ \\
\hline & Female & $257(63.6)$ \\
\hline \multirow[t]{5}{*}{2.} & Birth year & \\
\hline & $1980-1985$ & $21(5.0)$ \\
\hline & $1986-1990$ & $45(11.0)$ \\
\hline & $1991-1995$ & $80(20.0)$ \\
\hline & $1996-2000$ & $258(64.0)$ \\
\hline \multirow[t]{3}{*}{3.} & \multicolumn{2}{|c|}{ Place of Growing Up } \\
\hline & Urban area & $237(58.7)$ \\
\hline & Countryside & $167(42.3)$ \\
\hline \multirow[t]{5}{*}{4.} & \multicolumn{2}{|l|}{ Education Level } \\
\hline & High school & $4(1)$ \\
\hline & Undergraduate & $325(80.4)$ \\
\hline & Graduate & $72(17.8)$ \\
\hline & Doctorate & $3(0.7)$ \\
\hline \multirow[t]{4}{*}{5.} & \multicolumn{2}{|c|}{ Organizational Experience } \\
\hline & Less than a year & $76(18.8)$ \\
\hline & $1-5$ years & $251(62.1)$ \\
\hline & More than 5 years & $77(19.1)$ \\
\hline
\end{tabular}

\subsection{Procedure and Instrument}

Development of the instruments was done through several stages. As a part of the study, researchers conducted a focus-group discussion collaborating with other experts who were considered eligible for the research theme. The focus group discussion results contributed to the construction of the instrument used in the study. Other objectives of the focus-group discussion were to explore the extent of ILT studies in Indonesia and formulate aspects to investigate particularly in the country's context. The focus-group discussion results became the basis to formulate quantitative and qualitative question items. Instruments were then rated by fellow researchers in social and industrial/organizational fields to obtain expert judgment. After obtaining expert judgment, the instruments were tested to 10 participants to gather feedbacks about the comprehensibility.

At the beginning of questionnaire, researchers provided brief description of the study such as information about the research team, objective of the study, and informed consent. Participants were automatically considered to agree with the terms if they proceeded to the next page. Then, participants were inquired to answer an open ended question which was accompanied by quantitative scales to confirm the answers and disclose their perceptions toward leadership. To explore perceptions on leadership prototypes, participants were required to answer an openended question namely "Describe three characteristics of a leader". In order to obtain additional information about the typicality and effectiveness of characteristics or leadership prototypes described, participants were asked to fill twoitems scale to measure their perception about how typical and effective each character in a leader, ranging from 1 to 7. Lastly, participants were requested to fill their demographic details.

\subsection{Analysis}

The qualitative data from the open-ended question were coded using thematic analysis technique, which is a method to identify, analyze, and formulate patterns within the data (Braun \& Clarke, 2006). In total, there were 1159 responses obtained. The responses were categorized by at least three coders to avoid bias in data comprehension. Researchers applied several steps to categorize each response: (1) getting accustomed with the data; (2) generating initial codes; (3) looking for themes; (4) reviewing themes; and (5) defining and naming themes to several prototypes. Responses that could not fit existing categories were excluded and categorized as undefined. Finally, the categorization resulted in four major leadership prototypes.

Quantitative data from the scale were analyzed using one-way ANOVA. The analysis aimed to examine the difference in perception about the how typical and effective each characteristic in leadership. Difference in the extent of characteristic typicality could show which prototypes were considered to be more common for leader, while the difference in characteristic effectiveness showed how the prototypes were perceived to influence effective leadership. 


\section{Result}

Qualitative data showed the leadership prototypes according to participants while quantitative data showed the results of analysis of variance on the scale about how typical and effective those prototypes are.

\subsection{Leadership Prototype}

Based on the categorization of 1159 responses, there were four major themes of leadership prototypes: moral (41.07\%), generally-competent $(29.42 \%)$, charismatic $(20.79 \%)$, and conscientious $(8.71 \%)$. Table 2 shows detailed description of themes that emerged from qualitative data.

\subsubsection{Moral}

Moral is a leadership prototype with the highest number of responses compared to the other three prototypes. This leadership prototype is related to moral values and ethics. There are several sub-categories in this prototype: responsible $(8.46 \%)$, honest $(7.68 \%)$, considerate $(6.38 \%)$, embracing $(6.13 \%)$, righteous $(4.40 \%)$, reliable $(3.88 \%)$, virtuous $(1.38 \%)$, patriotism $(1.29 \%)$, humble $(1.04 \%)$, and serving $(0.43 \%)$. Sample of responses that described this prototype are the following

"Responsible toward his work (it means having commitment to finish tasks and taking risks)." (Responsible)

"Humble and coming down from his position to get closer and more equal with his subordinates. With certain boundaries." (Embracing)

\begin{tabular}{|c|c|c|c|}
\hline \multicolumn{2}{|c|}{ Category } & \multirow{2}{*}{$\frac{\mathbf{N}}{476}$} & \multirow{2}{*}{$\begin{array}{c}\% \\
41.07 \%\end{array}$} \\
\hline 1. & Moral & & \\
\hline & Responsible & 98 & $8.46 \%$ \\
\hline & Honest & 89 & $7.68 \%$ \\
\hline & considerate & 74 & $6.38 \%$ \\
\hline & Embracing & 71 & $6.13 \%$ \\
\hline & Righteous & 51 & $4.40 \%$ \\
\hline & Reliable & 45 & $3.88 \%$ \\
\hline & Virtuous & 16 & $1.38 \%$ \\
\hline & Patriotism & 15 & $1.29 \%$ \\
\hline & Humble & 12 & $1.04 \%$ \\
\hline & Serving & 5 & $0.43 \%$ \\
\hline \multirow[t]{4}{*}{2.} & Generally-competent & 341 & $29.42 \%$ \\
\hline & Technically-competent & 202 & $17.43 \%$ \\
\hline & Intelligent & 83 & $7.16 \%$ \\
\hline & Socially-competent & 56 & $4.83 \%$ \\
\hline \multirow[t]{10}{*}{3.} & Charismatic & 241 & $20.79 \%$ \\
\hline & Charismatic & 74 & $6.38 \%$ \\
\hline & Wise & 64 & $5.52 \%$ \\
\hline & Guiding & 24 & $2.07 \%$ \\
\hline & Role-model & 22 & $1.90 \%$ \\
\hline & Influencing & 18 & $1.55 \%$ \\
\hline & Emotionally stable & 15 & $1.29 \%$ \\
\hline & Motivating & 10 & $0.86 \%$ \\
\hline & Courageous & 9 & $0.78 \%$ \\
\hline & inspiring & 5 & $0.43 \%$ \\
\hline \multirow[t]{6}{*}{4.} & Conscientious & 101 & $8.71 \%$ \\
\hline & Goal-oriented & 46 & $3.97 \%$ \\
\hline & Disciplined & 32 & $2.76 \%$ \\
\hline & Determined & 9 & $0.78 \%$ \\
\hline & Committed & 7 & $0.60 \%$ \\
\hline & Hardworking & 7 & $0.60 \%$ \\
\hline
\end{tabular}

\subsubsection{Generally-Competent}

Generally-competent is a leadership prototype related to the ability in solving various problems. Several subcategories of this prototype are technically-competent (17.43\%), intelligent (7.16\%), and socially-competent (4.83\%). Response samples that describe this prototype are:

"Having broad knowledge about the issues within his leadership domain." (Intelligent)

"Able to make decision aptly and quickly." (Technically competent)

\subsubsection{Charismatic}

Charismatic is a leadership prototype related to the charm and appeal of a leader that makes people follow his or her lead. Sub-categories within this prototype are charismatic $(6.38 \%)$, wise $(5.52 \%)$, guiding (2.07\%), role-model $(1.90 \%)$, influencing $(1.55 \%)$, emotionally stable $(1.29 \%)$, motivating $(0.86 \%)$, courageous $(0.78 \%)$, and inspiring

$(0.43 \%)$. Some of the responses that describe this prototype are:

"Can be a model." (Wise)

"Mentally and emotionally stable." (Emotionally stable)

\subsubsection{Conscientious}

Conscientious is a prototype related to discipline to work on specific objective. There are some sub-categories within the prototype: conscientious (8.71\%), goal-oriented (3.97\%), disciplined (2.76\%), determined (0.78\%), 
committed (0.60\%), and hardworking (0.60\%). Responses that illustrate this prototype are "Commitment.", "Hard worker."

\subsection{Typicality and Effectiveness of Leadership Prototypes}

Results of quantitative data analysis on the scale about how typical the characteristic described by participants depict leadership showed a significant difference between aforementioned leadership prototypes with $p<.05$ for three conditions $[F(3,1155)=3.513, p=.015]$. Post hoc comparisons showed significant difference between conscientious $(M=6.406, S D=.777)$ and charismatic $(\mathrm{M}=6.062, \mathrm{SD}=1.0045)$ prototypes in typical leadership. Meanwhile, there was no significant difference between moral $(\mathrm{M}=6.227, \mathrm{SD}=.977)$ and generally-competent $(\mathrm{M}$ $=6.214, \mathrm{SD}=.87$ ) prototypes. According to overall result of one-way ANOVA, there was significant difference between the themes. However, at the level of prototypes, significant difference was only found between charismatic and conscientious prototypes, while other prototypes did not show such difference.

Table-3. Perception of how typical and effective each leadership prototype perceived.

\begin{tabular}{l|c|c|c|c|c|c|c|c}
\hline \multirow{2}{*}{ Categorization } & \multirow{2}{*}{$\mathbf{N}$} & \multicolumn{3}{|c|}{ Typical } & \multicolumn{4}{c}{ Effective } \\
\cline { 3 - 10 } & & $\mathbf{M}($ SD) & Min & Max & & M (SD) & Min & Max \\
\hline Moral & 476 & $6.23(0.98)$ & 1.0 & 7.0 & & $6.42(0.80)$ & 2.0 & 7.0 \\
\hline Generally-Competent & 341 & $6.21(0.87)$ & 3.0 & 7.0 & & $6.41(0.77)$ & 4.0 & 7.0 \\
\hline Charismatic & 241 & $6.06(1.00)$ & 1.0 & 7.0 & & $6.25(0.86)$ & 3.0 & 7.0 \\
\hline Conscientious & 101 & $6.41(0.78)$ & 5.0 & 7.0 & & $6.29(0.84)$ & 4.0 & 7.0 \\
\hline Total & 1159 & $6.20(0.94)$ & 1.0 & 7.0 & & $6.37(0.81)$ & 2.0 & 7.0 \\
\hline
\end{tabular}

Scores for effectiveness of leadership characteristics also showed significant difference between prototypes with $p<.05$ in three conditions $[F(3,1155)=2.996, p=.03]$. Post hoc comparisons showed significant difference between moral $(M=6.418, S D=.802)$ and charismatic $(M=6.249, \mathrm{SD}=.864)$ prototypes in effective leadership. Meanwhile, there was no significant difference between generally-competent $(M=6.41, S D=.768)$ and conscientious $(M=6.287, S D=.841)$ prototypes. Based on the overall result of one-way ANOVA, there was significant difference between the themes. Even so, at the level of prototypes, significant difference was only found between charismatic and moral prototypes, while other prototypes did not exhibit such difference. Table 3 summarizes the findings.

\section{Discussion}

The goal of this study was to discover Implicit Leadership Theory in Indonesia by exploring leadership prototype based on perception of Indonesian Millennials. Researchers employed few qualitative and quantitative questions to achieve the purpose. Categorization of the qualitative data generated some themes describing leadership prototypes which were then clarified for its typicality to describe leaders and effectiveness in leadership roles by utilizing the quantitative questions. The four main themes emerged were moral, generally-competent, charismatic, and conscientious.

Firstly, morality is considered as an important aspect by participants to describe characteristic of leadership. Based on the result of data analysis, the characteristics covered in this prototype were responsible to the duties, honest to oneself and members, attentive to followers, and protective of others. This finding has similarities with research conducted among Chinese participants, that personal morality is the most expected character of a leader (Ling, Chia, \& Fang, 2000). Although Chinese Implicit Leadership Theory (CILT) and Indonesian Implicit Leadership Theory suggested by our finding at a glance look similar, however moral prototype in Indonesia's social context constitutes different explanation.

Referring to leadership style, Indonesia adheres to paternalistic leadership, that leadership is reflected in personal moral integrity that we normally in father figure. Countries that adhere to paternalistic leadership, such as Indonesia, prioritize superior leaders, i.e. individuals who can give example, virtuous, have great sense of responsibility, and discipline (Irawanto, Ramsey, \& Ryan, 2011). Hence, religiosity could offer an alternative explanation about the reason why most of participants considered morality as leadership prototype. As a nation which holds tightly in the principles of religiosity, people in Indonesia emphasize the importance of moral values in their daily life. Religion alone raises awareness and develops moral behavior of individuals (Abun \& Cajindos, 2014). Religion and moral are related and supporting each other. Moral is part of religious standards that are expected to be implemented and become integral part of individuals (Rossano, 2008). Moral prototype as mentioned by the participants to describe leadership indicated their belief about leadership which might be influenced by social and religious values hold by the society.

Following the moral, generally-competent emerged as a leadership prototype which was also described by the participants. They considered the typical characteristics of leadership were intelligent, demonstrate good technical ability to lead, and competent in building social relationships. This finding supports the previous studies of Offermann. et al. (1994) and Offermann and Coats (2018) indicated that intelligence is part of implicit leadership theories as effective leadership. In addition, it is also accordance with the interpersonal competence factor in CILT with social ability and intelligent as certain characteristics to describe leader (Ling et al., 2000).

Leadership prototype concerning social skills in Chinese and Indonesian society exists regarding the fact that both of countries are considered to hold collectivistic culture which emphasizes social relationship in their lives (Triandis, 1995). In Indonesia, this practice could be found in some aspect of life. For instance, in most of situation in the society, people will consider taking musyawarah as a customary practices of consensus decision making which by involving many people in the society. Even until now, this traditional decision-making process is practiced in many levels in the society (Kawamura, 2011). Therefore, Indonesian people perceived leaders to have good social skills that can facilitate the values they hold concerning maintaining harmony in life. In addition, leader should be technically competent, as example leader should be able to utilize the development of technology to improve productivity and effectiveness. 
Third, charisma was a also described by participants to characterize leadership. It entailed some variety of positive leader's characters which can give emotional impact on their followers in achieving their goals (Antonakis, Bastardoz, Jacquart, \& Shamir, 2016). Charisma in many studies have very broad descriptions which emanate from verbal and nonverbal communication, and the balance between physical and mental health (Grabo, Spisak, \& van Vugt, 2017). Several subthemes describing charisma prototype in this study were wise in decision making, a guide for others, motivating and inspiring, also being a role model. The data showed that according to Indonesian millennials, charisma was not merely derived from physical virtue, instead they perceived charismatic leaders who could give positive influence on their followers. This finding does not support (Offermann. et al., 1994) who suggested that physical advantages are an appeal for leaders. However, this study confirms GLOBE study which found that specific aspects of charismatic leadership were universally endorsed (Den Hartog et al., 1999) and aligns with Parco-Tropicales and de Guzman (2014) finding that charismatic leadership could develop into wise leaders. According to Elias and Akintayo (2018) not everyone has the charisma of a leader. Thus, charisma is a valuable and special individual characteristic to be good leaders.

Finally, conscientious emerged as a main theme which shows that Indonesian millennials expect leaders to have clear goals, perseverance, and hard-working. As a trait, conscientious is shown by individuals who tend to be organized, responsible, and disciplined (McCrae \& Costa, 1987) and also is the strongest predictor of the effectiveness of task-oriented leaders (Derue, Nahrgang, Wellman, \& Humphrey, 2011). Considering task-oriented leadership implies the importance of organizing and increasing activities in which leaders must be able to provide structure, direction, reward/punishment, and group boundaries (Derue et al., 2011).

CILT also stated that leaders must be able to design strategic plans, unwavering and guarded, discipline, persevering, and hard-working. This is similar to research by Taormina and Selvarajah (2005) which stated that ASEAN community expects leaders with strategic thinking. Specifically, strategic thinking behavior relates to leaders with strategic vision, visionary, and far-sighted future in order to achieve competitive advantage (Ling et al., 2000). Conscientious characteristic also equivalent with Articulating Vision by Tsui, Wang, Xin, Zhang, and Fu (2004). Leaders must be able to clearly communicate their vision of the future of the organization. Since many studies that had found the equivalent to this conscientious prototype, we conclude that this prototype may be a universal aspect of leadership.

In addition to qualitative finding, quantitative data about how typical (common) each characteristic describes leadership were used to assess whether the four prototypes that emerged are perceived equally or differently in describing leadership. Result of one-way ANOVA showed difference for all conditions, however post-hoc comparisons only showed different typicality between conscientious and charismatic prototypes, and not the others. According to the mean scores of four main themes' that emerged in the study, leadership prototypes can be ranked from the highest mean score to the lowest in such order: conscientious, moral, generally competent, and charismatic. Regarding the analysis to examine the perception about how effective each prototype supports the leadership function, post-hoc comparisons showed significant difference between charismatic and conscientious. Meanwhile, the order of effectiveness from the highest mean score is moral, generally competent, conscientious, and charismatic.

These interesting findings did not appear to corroborate the results obtained from qualitative data analysis which showed that the order of leadership prototypes based on the percentage responses that emerged most; moral, general-competent, charismatic, and conscientious. In the absence of mutually reinforcing evidence between the qualitative and quantitative data, researchers cannot conclude which leadership prototypes are considered more typical or effective than others. However, the data showed that the four prototypes are considered as typical and effective with high score on the perception of how typical and effective each leadership prototypes is described.

Research conducted by Schyns and Schilling (2011) explained that in exploring ILT, leadership prototypes that emerged do not merely represent positive attributes on leadership. Sometimes negative attributes also appear in describing leadership. Junker and van Dick (2014) explained this as a dimension of leadership prototypes that includes norms, where typicality is the general character to label leaders, and valence that shows positive (or effective), negative, or neutral prototypes. According to Indonesian millennials, leadership prototypes that emerged from this study are not only typical prototype, but also positive prototype that supports leadership functions effectiveness.

\section{Conclusion}

Based on the results of this study, there are four main prototypes of leadership expected by Indonesian millennials, namely moral, generally-competent, charismatic, and conscientious. In addition, the perception on how typical and effective the four prototypes were seen as typical and effective by Indonesian millennials.

\section{Limitation \& Future Research}

Limitation of this study is the number of participants was only 404 and had not represented all Indonesian millennial in 34 provinces in Indonesia. In addition, 99\% of the participants have received tertiary education whilst in reality there are still many Indonesian millennials who have not yet received tertiary education. According to researchers, educational background has influence on participants' perception about leadership. For further research, a scale can be constructed based on the four leadership prototypes from this study to confirm the results of this study.

\section{References}

Abun, F. D., \& Cajindos, R. (2014). The effect of religion toward moral values of college students in Locos Sur, Philippines. E-international Scientific Researcg Journal, 4(3), 181-196.

Antonakis, J., Bastardoz, N., Jacquart, P., \& Shamir, B. (2016). Charisma: An Ill-defined and Ill-measured gift. Annual Review of Organizational Psychology and Organizational Behavior, 3(1), 293-319. Available at: https://doi.org/10.1 146/annurev-orgpsych041015-062305.

As'Ad, M., Anggoro, W. J., \& Virdanianty, M. (2011). Exploration study of the Java model leadership extract: Asta Brata. Jurnal Psikologi, 38(2), 228-239. Available at: Journal of Psychology. 
Avolio, B. J., Walumbwa, F. O., \& Weber, T. J. (2009). Leadership: Current theories, research, and future directions. Annual Review of Psychology, 60(1), 42 1-449. Available at: https://doi.org/10.1146/annurev.psych.60.110707.163621.

Barford, I., \& Hester, P. (2011). Analysis of generation $Y$ workforce motivation using multiattribute utility theory. Virginia: Defense Acquisition Univ Ft Belvoir Va.

Braun, V., \& Clarke, V. (2006). Using thematic analysis in psychology. Qualitative Research in Psychology, 3(2), 77-101. Available at: https://doi.org/10.1191/1478088706qp063oa.

Brodbeck, F. C., Frese, M., Akerblom, S., Audia, G., Bakacsi, G., Bendova, H., \& Brenk, K. (2000). Cultural variation of leadership prototypes across 22 European countries. Journal of Occupational and Organizational Psychology, 73(1), 1-29.

Central Statistics Agency. (2013). Projection of Indonesian population 2010-2035. Central Bureau of Statistics.

Day, D. V., Fleenor, J. W., Atwater, L. E., Sturm, R. E., \& McKee, R. A. (2014). Advances in leader and leadership development: A review of 25 years of research and theory. The Leadership Quarterly, 25(1), 63-82. Available at: https://doi.org/10.1016/j.leaqua.2013.11.004.

Den Hartog, D. N., House, R. J., Hanges, P. J., Ruiz-Quintanilla, S. A., Dorfman, P. W., Abdalla, I. A., \& Akande, A. (1999). Culture specific and cross-culturally generalizable implicit leadership theories: Are attributes of charismatic/transformational leadership universally endorsed? The leadership quarterly, 10(2), 219-256.

Derue, D. S., Nahrgang, J. D., Wellman, N., \& Humphrey, S. E. (2011). Trait and behavioral theories of leadership: An integration and metaanalytic test of their relative validity. Personnel Psychology, 64(1), 7-52. Available at: https://doi.org/10.1111/j.17446570.2010.01201.x.

Elias, S., \& Akintayo, M. O. (2018). Charismatic leadership studies- past, present and future: Theorizing the potential of charismatic rhetoric research in doctor of education programs. International Journal of Social Science Research, 7(1), 1-25. Available at: https://doi.org/10.5296/ijssr.v7i1.12959.

Grabo, A., Spisak, B. R., \& van Vugt, M. (2017). Charisma as signal: An evolutionary perspective on charismatic leadership. The Leadership Quarterly, 28(4), 473-485. Available at: https://doi.org/10.1016/j.leaqua.2017.05.001.

Harwiki, W. (2013). The influence of servant leadership on organization culture, organizational commitment, organizational citizenship behavior and employeesâ $€^{\mathrm{TM}}$ performance (Study of outstanding cooperatives in East Java Province, Indonesia). Journal of Economics and Behavioral Studies, 5(12), 876-885.

Helmi, A. F., \& Arisudana, I. (2009). Transformational leadership, trust and knowledge sharing in organizations. Journal of Psychology, 36(2), 95 - 105. Available at: https://doi.org/10.22146/jpsi.7888.

Irawanto, D. W., Ramsey, P. L., \& Ryan, J. C. (2011). Tailoring leadership theory to Indonesian culture. Global Business Review, 12(3), 355366. Available at: https://doi.org/10.1177/097215091101200301.

Junker, N. M., \& van Dick, R. (2014). Implicit theories in organizational settings: A systematic review and research agenda of implicit leadership and followership theories. The Leadership Quarterly, 25(6), 1154-1173. Available at: https://doi.org/10.1016/j.leaqua.2014.09.002.

Kawamura, K. (2011). Consensus and democracy in Indonesia: Musyawarah-Mufakat revisited. IDE Discussion Paper. No. 308. Retrieved from: http://hdl.handle.net/2344/1091 or http://dx.doi.org/10.2139/ssrn.2280935.

Ling, W., Chia, R. C., \& Fang, L. (2000). Chinese implicit leadership theory. The Journal of Social Psychology, 140(6), 729-739. Available at: https://doi.org/10.1080/00224540009600513.

Lord, R. G., Foti, R. J., \& Phillips, J. S. (1982). A theory of leadership categorization. In J. G. Hunt, U. Sekaran, \& C. A. Schriesheim (Eds.), Leadership: Beyond establishment views (pp. 104-121). Carbondale, IL: Southern Illinois University Press.

McCrae, R. R., \& Costa, P. T. (1987). Validation of the five-factor model of personality across instruments and observers. Journal of Personality and Social Psychology, 52(1), 81-90. Available at: https://doi.org/10.1037/0022-3514.52.1.81.

Offermann, L. R., \& Coats, M. R. (2018). Implicit theories of leadership: Stability and change over two decades. The Leadership Quarterly, 29(4), 513-522. Available at: https://doi.org/10.1016/j.leaqua.2017.12.003.

Offermann., L. R., Kennedy, J. K., \& Wirtz, P. W. (1994). Implicit leadership theories: Content, structure, and generalizability. The Leadership Quarterly, 5(1), 43-58. Available at: https://doi.org/10.1016/1048-9843(94)90005-1.

Parco-Tropicales, M., \& de Guzman, A. B. (2014). A structural equation model (SEM) of the impact of transformational, visionary, charismatic and ethical leadership styles on the development of wise leadership among Filipino private secondary school principals. Asia Pacific Education Review, 15(4), 547-559. Available at: https://doi.org/10.1007/s12564-014-9346-5.

Phillips, J. S., \& Lord, R. G. (1986). Notes on the practical and theoretical consequences of implicit leadership theories for the future of leadership measurement. Journal of Management, 12(1), 31-41. Available at: https://doi.org/10.1177/014920638601200104.

Robert, L. G., Foti, R. J., \& De Vader, C. L. (1984). A test of leadership categorization theory: Internal structure, information processing, and leadership perceptions. Organizational Behavior and Human Performance, 34(3), 343-378. Available at: https://doi.org/10.1016/0030-5073(84)90043-6.

Ronald, B. (2014). Comprehensive leadership review-literature, theories and research. Advances in Management, 7(5), 52-66.

Rosch, E. (1978). Principle of categorization. In: E. Rosch, \& B. B. Lloyd (Eds.), Cognition and categorization (pp. 28-49). Hillsdale, NJ: Erlbaum.

Rossano, M. J. (2008). The moral faculty: Does religion promote "moral expertise"? The International Journal for the Psychology of Religion, 18(3), 169-194. Available at: https://doi.org/10.1080/10508610802115727.

Schyns, B., \& Schilling, J. (2011). Implicit leadership theories: Think leader, think effective? Journal of Management Inquiry, 20(2), 141-150. Available at: https://doi.org/10.1177/1056492610375989.

Suseno, M. N., \& Sugiyanto. (2010). The effect of social support and transformational leadership on organizational commitment with work motivation mediators. Journal of Psychology, 37(1), 94-109.

Taormina, R. J., \& Selvarajah, C. (2005). Perceptions of leadership excellence in ASEAN nations. Leadership, 1(3), 299-322. Available at: https://doi.org/10.1177/1742715005054439.

Triandis, H. C. (1995). New directions in social psychology. New York: Westview Press.

Tsui, A. S., Wang, H., Xin, K., Zhang, L., \& Fu, P. P. (2004). Let a thousand flowers bloom: Variation of leadership styles among Chinese CEOs. Organizational Dynamics, 33(1), 5-20. Available at: https://doi.org/10.1016/j.orgdyn.2003.11.002.

Widianto, S., \& Wilderom, C. P. M. (2017). Transformational leadership, service climate, psychological capital and job performance/engagement. Academy of Management Proceedings Academy of Management, 1-17. 